\title{
DFT calculations to investigate silver ions as a virucide from SARS-CoV-2
}

\author{
Jocelia Silva Machado Rodrigues ${ }^{1}$. Aldimar Machado Rodrigues ${ }^{2}$. Divanizia do Nascimento Souza ${ }^{3}$. \\ Erico Raimundo Pereira de Novais ${ }^{4}$ (D) . Alzeir Machado Rodrigues ${ }^{5}$. Glaura Caroena Azevedo de Oliveira ${ }^{4}$. \\ Andrea de Lima Ferreira Novais ${ }^{6}$
}

Received: 7 July 2021 / Accepted: 29 September 2021 / Published online: 13 October 2021

(C) The Author(s), under exclusive licence to Springer-Verlag GmbH Germany, part of Springer Nature 2021

\begin{abstract}
The world has face the COVID-19 pandemic which has already caused millions of death. Due to the urgency in fighting the virus, we study five residues of free amino acids present in the structure of the SARS-CoV-2 spike protein (S). We investigated the spontaneous interaction between amino acids and silver ions $\left(\mathrm{Ag}^{+}\right)$, considering these ions as a virucide chemical agent for SARS-CoV-2. The amino acid- $\mathrm{Ag}^{+}$systems were investigated in a gaseous medium and a simulated water environment was described with a continuum model (PCM) the calculations were performed within the framework of density functional theory (DFT). Calculations related to the occupied orbitals of higher energy showed that $\mathrm{Ag}^{+}$has a tendency to interact with the nitrile groups $(-\mathrm{NH})$. The negative values of the Gibbs free energies show that the interaction process between amino acids- $\mathrm{Ag}^{+}$in both media occurs spontaneously. There is a decrease in Gibbs free energy from the amino acid- $\mathrm{Ag}^{+}$interactions immersed in a water solvation simulator.
\end{abstract}

Keywords COVID-19 $\cdot$ Silver ions $\cdot$ Inactivation $\cdot$ DFT

\section{Introduction}

Silver nanoparticles (AgNPs) have been studied due to their great potential for applications such as targeted drug delivery carriers because of their antiviral and antibacterial properties. Those materials have the potential for antimicrobial action against various bacteria, fungi, and viruses $[1,2]$. In nanomedicine, the use of metal

Erico Raimundo Pereira de Novais ericonovais@gmail.com

1 Programa de Pós-Graduação em Química, Universidade Federal do Sul e Sudeste do Pará, Marabá, Pará, Brazil

2 Instituto Federal do Pará, Altamira, Pará, Brazil

3 Departamento de Física, Universidade Federal de Sergipe, Aracaju, Sergipe, Brazil

4 Faculdade de Física, Universidade Federal do Sul e Sudeste do Pará, Marabá, Pará, Brazil

5 Instituto Federal do Ceará, Acopiara, Ceará, Brazil

6 Faculdade de Engeharia Mecânica, Universidade Federal do Sul e Sudeste do Pará, Marabá, Pará, Brazil nanoparticles as drug carriers that can accumulate close to target cells and have an excellent therapeutic effect is well established [3].

Several authors have studied the potential antiviral actions of AgNPs against various human viruses, including those that cause respiratory diseases. AgNPs studies have demonstrated this potent antiviral action against various human pathogenic viruses such as Respiratory syncytial virus (RSV), Influenza virus, Norovirus, Hepatitis B virus (HBV), and Human immunodeficiency virus (HIV) [4, 5]. Several studies suggest that AgNPs have presumed antiviral properties [6-10] .

Silver nanoclusters have also been studied due to interactions between $\mathrm{Ag}^{+3} \mathrm{NC}$ with Cys and Gly [6] and Ag NCs with Trp and His [7, 8]. The interactions of amino acids with $\mathrm{Ag}^{+3}$ clusters serve as catalytic models of $\mathrm{Ag}$ nanoparticles [6]. Previous works have shown that $\mathrm{Ag}_{2} \mathrm{~S}$ nanoclusters (NCs) exhibit highly efficient antiviral activity when using the porcine epidemic diarrhea virus (PEDV) as a coronavirus model $[9,10]$.

In another experimental and theoretical study, the authors calculated the Gibbs free energies of the complexes formed between $\mathrm{Ag}^{+}$ions, $\mathrm{Ag}$ atoms, and two-atom $\mathrm{Ag}$ clusters with the amino acid's various functional groups $[7,8,11]$. 
Some theoretical and experimental studies on amino acids and silver ions have been performed by other authors $[1,11-14]$. In one of the works [6,9] the silver ion complex, $\mathrm{Ag}^{+}$, was examined with amino acid using hybrid density functional theory at the B3LYP/DZVP level.

The silver $\mathrm{Ag}^{+}$ions come from the dissociation of different salts and from the surfaces of the oxidized silver nanoparticles. The dissociation rate depends on the chemical and surface properties, the size of the particles, and the surrounding environment [15].

In water, as in biological systems, the chemical complexity of the constituent elements of the medium determines the properties of Ag. Silver is a transition metal that has positively charged ions. In water, in order for silver ions to become stable they are associated with negative ions, called ligands. A small percentage of the total dissolved silver remains as a free ion, depending on the concentrations of the different negatively charged ligands and the strength of the silver ion bond with each ligand.

Antibacterial activity of different forms of silver, including ions $\left(\mathrm{Ag}^{+}\right)$, and silver nanoparticles (AgNPs) has been reported [16-18]. Cell death caused by the deenergization of the cell membrane can be caused by low concentrations of $\mathrm{Ag}$, which causes the massive escape of protons $\left(\mathrm{H}^{+}\right)$of the membrane [19].

Other studies show structural changes in the cell membrane and vacuoles due to the deposition of small dense granules, formed by silver ions and sulfur, destabilizing the membrane and leading to cell lysis [20, 21]. These granules inhibit cell division and damage the cell envelope and bacterial content. Bacterial cells increase in size, and the cytoplasmic membrane, cytoplasmic content, and outer layers of the cell show structural abnormalities [22]. Small dense granules were also observed to be deposited within cells. The presence of silver ions and sulfur in these granules suggests an interaction with nucleic acids, weakening DNA replication [23].

Several pathogenic viruses, including Chikungunya, dengue, influenza, SARS-CoV, MERS-CoV, and SARS$\mathrm{CoV}-2$ viruses, are protected by a viral membrane, which is a capsid that fuses with a cell initiating the infection process $[24,25]$.

SARS-CoV is identified as the causative agent of severe acute respiratory syndrome. SARS-CoV appears similar to other coronaviruses in the structure of the virus and the organization of the genome. It is known to other coronaviruses that the peak glycoprotein (S) is necessary for viral attachment to permissive cells and the fusion of the enveloped virus with the host cell membrane [26].

The viral capsid is a lipoprotein envelope composed of phospholipid molecules and structural glycoproteins inserted in the lipid bilayer, spike (S) proteins. The cell fusion process is initiated and completed by the spike
(S) protein.[27, 28] The SARS-CoV-2 infection process is extensively studied [25]. Viral infection occurs with cell fusion, utilizing conformational changes of "unfolding" that are energetically unfavorable [28].

Silver ions can cause changes in the structure of the cell membrane, changing its morphology, in addition to being able to enter the cell and destroy different components by interacting with thiol groups, changing the respiratory function of cells and can also interact with phosphate groups of molecules like DNA, thereby preventing the replication or transcription of messenger RNA into new proteins [19-21, 23].

Due to the urgency in fighting the virus, in this work, we investigated the interaction affinity between five residues of amino acids that form the protein spike (S) silver ions $\mathrm{Ag}^{+}$.

\section{Computational details}

One performs all theoretical calculations via the Gaussian09 suite of packages within the framework of density functional theory (DFT) [29]. The computational program performs $\mathrm{Ab}$ Initio calculations and describes the energy of exchange and correlation of structures in a gaseous environment and water solvation simulator.

As a first step, a test was carried out to observe the tendency of silver ions $\left(\mathrm{Ag}^{+}\right)$to interact with the SARS$\mathrm{CoV}-2$ protein spike (S). It was observed that there are some surface regions in which the silver ions are more likely to interact with the amino acid residues of the protein. Thus, it was observed that the residues of five amino acids glutamate (GLU), isoleucine (ILE), leucine (LEU), threonine (THR), and lysine (LYS) showed greater interaction with $\mathrm{Ag}^{+}$ions, which initiated the proposed calculations in the search.

The molecular structure of the spike (S) protein that forms SARS-CoV-2 was obtained from Protein Database [30] (http://www.rcsb.org) from Electron Microscopy with resolution 3.7. Yurkovetskiy et al. [31]

The UCSF Chimera software was used to aggregate the $\mathrm{Ag}^{+}$ions in the surface regions of charge density that showed a greater tendency for interaction between silver ions and residues of the amino acids GLU, ILE, LEU, THR and LYS [32]. The molecular structures of the amino acids are obtained from the PubChem database.

After this process, optimizations of the molecular geometric structure of the amino acids were carried out, initially in the gas phase when applying the density functional theory (DFT) with the hybrid functional B3LYP (exchange function with three Becke parameters combined with the correlation function of Lee, Yang, and Parr, LYP) [33, 34] in the DGDZVP Gaussian basis set [29].

After optimizing the structures with their minimum energies in the gaseous phase, Gibbs $\left(\Delta G^{0}\right)$ free energies 
were calculated under standard conditions (nominally $1 \mathrm{~atm}$ and $298.15 \mathrm{~K}$ ), electrostatic potential maps (MEPs), and occupied orbitals of highest energy (HOMO).

Then, the optimized structures underwent a new geometric optimization process in a simulated water environment (simulating an aqueous environment). With the aqueous environment, the minimum energy structures and the calculation of Gibbs free energies were obtained under standard conditions.

Continuous Polarizable Model (PCM) [8] in the SelfConsistent Reaction Field (SCRF) was used to describe the solvation effect in the water [9]. Both the gas phase and a simulated water environment had minimum energy configurations calculated from the optimization geometry of amino acids and silver ion structures.

\section{Results and discussion}

\section{Adhesion regions and spontaneity of $\mathrm{Ag}^{+}$- amino acids.}

The amino and carboxyl groups of the amino acids can function as active sites if the geometric configuration of the macromolecule does not offer a steric impediment to the approach of a potential ligand, as these groups are highly polarized. The active sites of a viral protein are responsible for interacting with the host cell. Those sites can contact a ligand with the capacity to neutralize the viral protein [35].
The $\mathrm{Ag}^{+}$ions behave as a ligand, joining the negatively charged poles of the amino and carboxyl groups of the amino acids.

SARS-CoV-2 has approximately 29 viral proteins, including the peak glycoprotein, or spike (S), which facilitates the entry of the virus into the host cell by binding to the cell receptor and membrane fusion. Another protein with relevant importance is the nucleocapsid, or $\mathrm{N}$ protein, which functions to regulate the viral replication process [36]. Figure 1 shows protein spike (S) and the regions where the interactions between $\mathrm{Ag}^{+}$and amino acids occurred. As observed in this figure, the majority of regions where $\mathrm{Ag}^{+}$ ions are in the protein spike (S) are mainly composed of the amino acids glutamate (GLU), isoleucine (ILE), leucine (LEU), threonine (THR), and lysine (LYS) residues. In regions I and III (Fig. 1), there is a preponderance of THRtype amino acid residues, while in II, this is GLU and in IV it is LEU. From these observations, we started to perform the DFT calculations of the unions between these amino acids and the silver ion [37]. To disperse $\mathrm{Ag}^{+}$onto the protein surface, we used the Chimera software, which has the application field model-assisted building with refinement energy force field (AMBER) as a principle [38], enabling the regions of the molecule with the highest occurrence of interactions between amino acids and $\mathrm{Ag}^{+}$ions to be identified.

Accurate knowledge of Gibbs free energy binding between the amino acid molecule and $\mathrm{Ag}^{+}$is necessary to provide an adequate minimum thermodynamic goal.

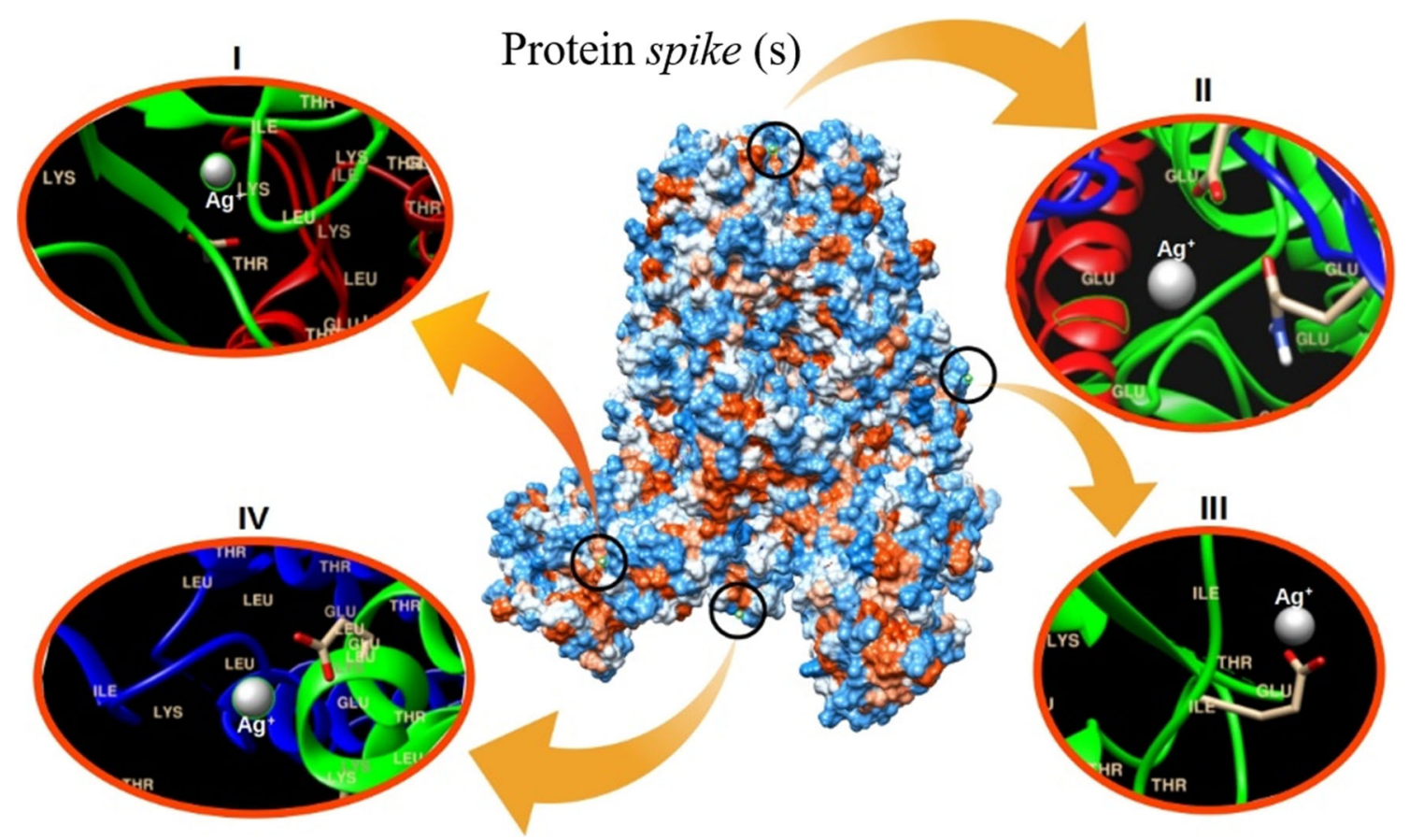

Fig. 1 Protein spike (s) and regions of interaction $\mathrm{Ag}^{+}$-amino acids 
Table 1 Free energies of Gibbs amino acid- $\mathrm{Ag}^{+}$interaction $\Delta \mathrm{G}^{0}$, in $\mathrm{KCal} / \mathrm{mol}$

\begin{tabular}{llllll}
\hline Phase & GLU-Ag $^{+}$ & ILE-Ag & LEU-Ag & THR-Ag & LYS-Ag \\
\hline Gaseous & -42.94 & -46.21 & -46.64 & -43.51 & -46.38 \\
Aqueous & -3.70 & -4.10 & -5.18 & -5.30 & -5.15 \\
\hline
\end{tabular}

The Gibbs free energy is significant for describing the equilibrium constant of the chemical reaction [39] among other parameters such as liquid-vapor phase equilibrium [40].

When the Gibbs free energy is negative $(\Delta G<0)$, this indicates that the process will occur spontaneously because of the increased entropy $(\Delta S>0)$, in a process known as exergonic $[41,42]$. We calculated the minimization of $\Delta G$ energy in the gaseous-liquid system to understand the phase equilibrium or thermodynamic balance [40].

The Gibbs energy depends on the chemical nature of the organism, the medium conditions, the reagents concentrations, and the intermolecular forces between the reaction participants [43]. We calculated the Gibbs free energy for the amino acid- $\mathrm{Ag}^{+}$systems, according to Eq. 1 .

Those calculations predicted the parameter $\Delta G^{0}$ from Eq. 1 for each interaction between amino acid- $\mathrm{Ag}^{+}$.

$\Delta G^{0}=\Delta G_{\left(\text {aminoacid }-A g^{+}\right)}^{0}-\left(\Delta G_{\text {aminoacid }}^{0}+\Delta G_{A g^{+}}^{0}\right)$

$\Delta G_{\left(\text {aminoacid }-\mathrm{Ag}^{+}\right)}^{0}$ is the Gibbs free energy of the complex amino acid- $\mathrm{Ag}^{+}$, the $\Delta G_{(\text {aminoacid })}^{0}$ parameter is the Gibbs free energy of each amino acid, and $\Delta G_{\mathrm{Ag}^{+}}^{0}$ is the Gibbs free energy of the $\mathrm{Ag}^{+}$ions.

Spontaneous processes have negative $\Delta G^{0}$ values, and more negative values of the free energy variation in a process indicate that it will be energetically more favorable [42]. Table 1 shows the $G^{0}$ values calculated according to Eq. 1. All values of Gibbs free energies are negative, which can indicate that the interaction processes between $\mathrm{Ag}^{+}$amino acids are spontaneous in both the gas phase and in a simulated water environment.

The values of the calculated Gibbs free energies (Table 1) are close to the values found in the literature [12, 44]. The negativity Gibbs free energy specifies that the adsorption process is spontaneous, therefore, it should be noted that enthalpy energy variation $(\Delta H<0)$ has a negative value which indicates that the adsorption process is exothermic [45].

\section{Molecular electrostatic potential of free amino acids and amino acids- $\mathbf{A g}^{+}$}

The molecular electrostatic potential (MEP) is a wellestablished procedure for the study of molecular reactive properties and to describe intermolecular interactions [46]. It is possible to identify the charge distributions in the molecules, the correlations between partial charges, the dipole moments, electronegativity, and chemical reactivity within the MEP diagram [47]. The molecular electrostatic potential diagram provides negative, positive, and neutral electrostatic regions in terms of the color gradient and is an index in the research of molecular structure properties [48]. Besides, the MEP diagram checks the most polarized surface regions of a molecule that indicates their reactivity or tendency to interact with other systems [48, 49].

The electrostatic potential scheme of structural optimizations of molecular geometries of free amino acids in the gas phase and the combination of amino acids and $\mathrm{Ag}^{+}$ions were calculated using the B3LYP/DGDZVP method (see Figs. 2 and 3).

Figure 2 shows the charge distribution and molecular electrostatic potential map for five free amino acids as a gaseous phase. The charges centered on each atom were calculated according to Mulliken's population analysis [50].

In electrostatic potential maps, the color red represents the most electronegative electrostatic potential with intense

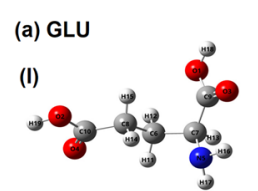

(II)

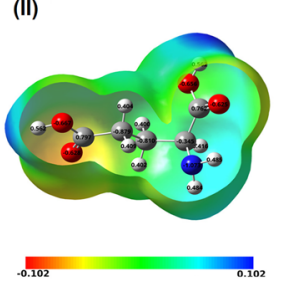

(b) ILE

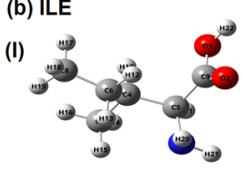

(II)

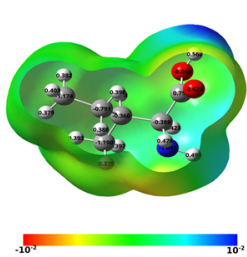

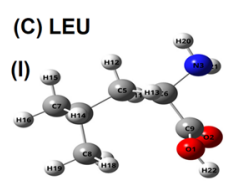

(II)

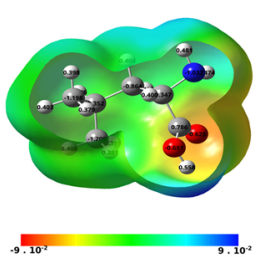

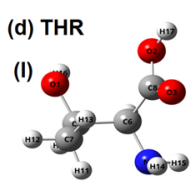

(II)

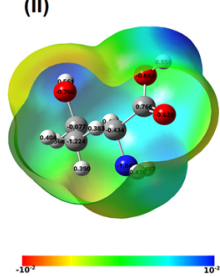

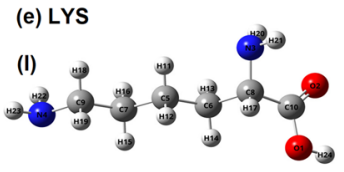

(II)



Fig. 2 Optimized structures, maps of electrostatic potentials (MEPs) of the GLU, ILE, LEU, THR, and LYS systems 


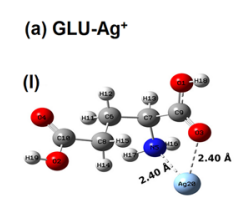

(II)

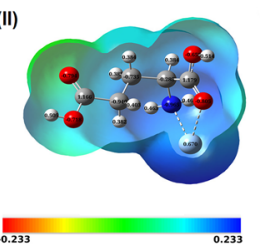

(b) ILE-Ag+

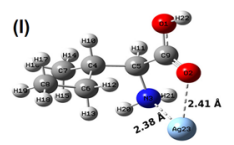

(II)

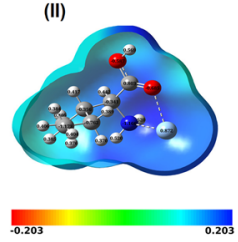



(II)

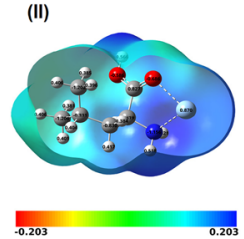

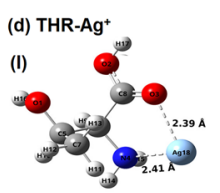

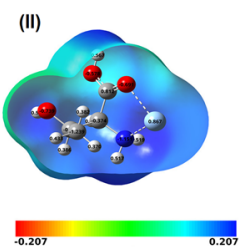

(e) LYS-Ag+

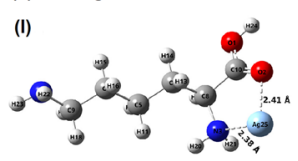

(II)

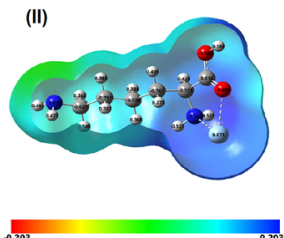

Fig. 3 Optimized structures and maps of electrostatic potentials (MEPs) of the GLU-Ag ${ }^{+}, \mathrm{ILE}-\mathrm{Ag}^{+}, \mathrm{LEU}-\mathrm{Ag}^{+}, \mathrm{THR}-\mathrm{Ag}^{+}, \mathrm{and} \mathrm{LYS}^{-\mathrm{Ag}^{+}}$ systems

repulsion, in which atoms tend to attract electrons (electrophilic). Blue indicates the most electropositive potential that has a strong attraction, while green shows that the electrostatic potential is zero.

Figure 2(aII) shows that the MEP surfaces of the GLU vary between -0.102 a.u for the deepest red and 0.102 a.u for the deepest blue. Figure 2(bII) also shows the ILE amino acid with $-10^{-2}$ a.u deepest red to $10^{-2}$ a.u deepest blue. As shown in Fig. 2(cII) the MEP surfaces of the LEU range from $-9 \times 10^{-2}$ a.u for the deepest red to $9 \times 10^{-2}$ a.u for the deepest blue. Figure 2(dII) also shows the THR amino acid with $-10^{-2}$ a.u deepest red to $10^{-2}$ a.u deepest blue. Similarly, Fig. 2(eII) shows that the MEP surfaces of LYS vary in the same range.

In Fig. 3, the red color represents the most electronegative electrostatic potential, while blue indicates the most electropositive potential. The figures inserted into it show highly polarized regions in the amino and carboxyl groups. The surface with negative potential is related to electrophilic attack, and the positive ones are related to nucleophilic reactivity. The blue spheres represent negatively charged poles centered on nitrogen atoms, and the red spheres are oxygen atoms that form carbonyls through the double bonds established with carbon atoms, graphite spheres. These negatively charged poles are regions with the relevant potential to establish electrostatic interactions with $\mathrm{Ag}^{+}$positively charged particles.
Figure 3(aII) shows that the MEP surfaces of the GLU$\mathrm{Ag}^{+}$range from -0.233 a.u deepest red to 0.233 a.u deepest blue. Figure 3(bII) also shows that the MEP surfaces of the ILE- $\mathrm{Ag}^{+}$range from -0.203 a.u deepest red to 0.203 a.u deepest blue. The same range is observed for MEP surfaces of the LEU-Ag+, as observed in Fig. 3(cII). Figure 3(dII) shows the MEP surfaces of the THR- $\mathrm{Ag}^{+}$ range from -0.207 a.u deepest red to 0.207 a.u deepest blue. In Fig. 3(eII), the MEP surfaces of LYS-Ag+ also varies from -0.203 a.u deeper red to 0.203 a.u deeper blue.

The MEPs of Fig. 3 also show that the molecular surface surrounding silver is highly positive for all systems, and poles of negatively charged surfaces present in the amino and carboxyl groups are reduced when these groups interact with the silver structure. In addition, silver acts as a major positive center in systems.

In GLU- $\mathrm{Ag}^{+}$, according to Mulliken's population analysis, silver has a charge of $+0.670 e$, in ILE- $\mathrm{Ag}^{+}$it has a charge of $+0.872 e$, in LEU- $\mathrm{Ag}^{+}$it has a charge of $+0.870 e$, in THR-Ag ${ }^{+}$it has charge of $+0.867 e$ and in $\mathrm{LYS}_{-\mathrm{ag}^{+}}{ }^{+}$it has a charge of $+0.871 e$.

\section{Occupied orbitals of highest energy of amino acids-Ag ${ }^{+}$}

Figure 4 shows the 3D graphs of the higher energy molecular orbitals (HOMOs) of the $\mathrm{Ag}^{+}$amino acid systems. The (a) GLU-Ag+

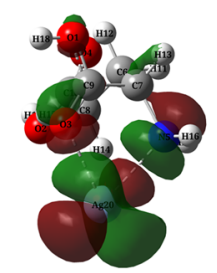

(b) ILE-Ag ${ }^{+}$

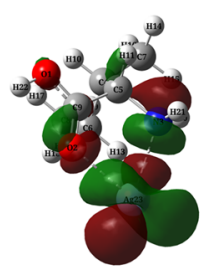

(c) LEU-Ag+

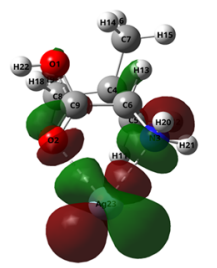

(d) THR-Ag+

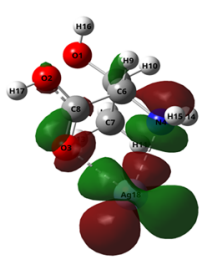

(e) LYS-Ag

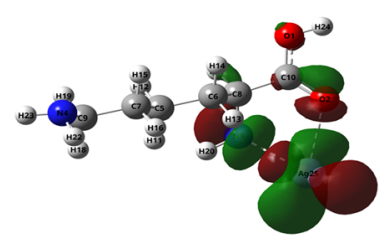

Fig. 4 Higher energy occupied orbitals, HOMOS for GLU-Ag ${ }^{+}, \mathrm{ILE}-\mathrm{Ag}^{+}, \mathrm{LEU}-\mathrm{Ag}^{+}, \mathrm{THR}-\mathrm{Ag}^{+}$, and LYS-Ag ${ }^{+}$systems 
red color in the illustrations of the orbitals represents the positive phase while the green color represents the negative phase. Orbital hybridization corresponds to the formation of the binding of the molecules of the amino acids and the $\mathrm{Ag}^{+}$.

Figure 4 also shows that the orbital distribution of HOMO in each amino acid was not uniform. This characteristic may have been caused by the presence of the transition metal $\left(\mathrm{Ag}^{+}\right)$in its electronic distribution.

The HOMOs showed that silver ions were present between the $-\mathrm{NH}_{2}$ and $-\mathrm{C}=\mathrm{O}$ groups. Also, the highest electronic density of HOMO was observed in $-\mathrm{NH}_{2}$. These results show that the electronic density of HOMO favors the interaction between the $\mathrm{Ag}^{+}$ion and the amino acid. The negative phases of the $\mathrm{Ag}^{+}$ions were linked to the positive ones of the oxygen atoms and the positive ones were linked to the negative ones of the nitrogen atoms.

The HOMOs showed that silver ions were present between the $-\mathrm{NH} 2$ and $-\mathrm{C}=\mathrm{O}$ groups. In addition, the highest electronic density of $\mathrm{HOMO}$ was observed in $-\mathrm{NH}_{2}$. These results show that the electronic density of HOMO favors the interaction between the $\mathrm{Ag}^{+}$ion and the amino acid. The negative phases of the $\mathrm{Ag}^{+}$ions were linked to the positive ones of oxygen atoms, and the positive ones were linked to the negative ones of nitrogen atoms.

Figure 4 shows that the interactions of $\mathrm{Ag}^{+}$ions are more favorable for the $-\mathrm{NH}_{2}$ groups than for $-\mathrm{C}=\mathrm{O}$ considering that the charge density involved in the first case is higher. This characteristic shows that $-\mathrm{NH}_{2}$ has a tendency to establish a coordinated bond, donating its pair of nonbinding electrons from the valence, which makes it a very strong Lewis base [51]. The results show that $\mathrm{Ag}^{+}$interacts with the nitrogen's of the amino group and with the carboxyl oxygen.

Table 2 shows the bond length $\left(\lambda_{l}\right)$ between the nitrogen and oxygen atoms of the systems composed of the amino acids- $\mathrm{Ag}^{+}$for the GLU, ILE, LEU, THR, and LYS structures.

The bond lengths between $\mathrm{N}_{5}-\mathrm{Ag}^{+}$in GLU amino acid has $2.40 \AA$ and $\mathrm{O}_{3}-\mathrm{Ag}^{+}$has $2.40 \AA$, but the value for the $\mathrm{N}_{5}$ $\mathrm{Ag}^{+}$both in ILE and LEU amino acid have the same value, $2.38 \AA$, and is smaller than GLU- $\mathrm{Ag}^{+}$. On the other hand,

Table 2 Bond length $\left(\lambda_{l}\right)$ between amino acids- $\mathrm{Ag}^{+}(\AA)$

\begin{tabular}{llllll}
\hline & GLU & ILE & LEU & THR & LYS \\
\hline $\mathrm{O}_{2}$ & & 2.41 & 2.41 & 2.39 & 2.41 \\
$\mathrm{O}_{3}$ & 2.40 & & & & \\
$\mathrm{~N}_{3}$ & & 2.38 & 2.41 & & 2.41 \\
$\mathrm{~N}_{4}$ & & & & 2.41 & \\
$\mathrm{~N}_{5}$ & 2.40 & & & & \\
\hline
\end{tabular}

the value for the $\mathrm{O}_{3}-\mathrm{Ag}^{+}$both in ILE-LEU-Ag ${ }^{+}, 2.41 \AA$, is slightly higher than GLU- $\mathrm{Ag}^{+}$.

The bond lengths for $\mathrm{N}^{-} \mathrm{Ag}^{+}$are slightly higher than the experimental value in silver complex I reported in the literature [52]. Table 2 shows the bond length between the nitrogen and oxygen atoms of the systems composed of the amino acids- $\mathrm{Ag}^{+}$for the THR and LYS structure.

The bond lengths between $\mathrm{N}_{4}-\mathrm{Ag}^{+}$in THR amino acid have values of $2.41 \AA$, while $\mathrm{O}_{2}-\mathrm{Ag}^{+} 2.39 \AA$ are larger when compared with GLU- $\mathrm{Ag}^{+}$, as can be seen in Table 2. On the contrary, the value for the $\mathrm{O}_{2}-\mathrm{Ag}^{+}$in both THR-Ag ${ }^{+}$and LYS- $\mathrm{Ag}^{+}$have the values $2.39 \AA$ and $2.41 \AA$, respectively. Amino acids that have hydrogen or alkyl groups in their side chains form bidentate complexes with $\mathrm{Ag}^{+}$; in these complexes, the $\mathrm{N}-\mathrm{Ag}^{+}$and $\mathrm{O}-\mathrm{Ag}^{+}$distances as shown in table 2 range from 2.38 to $2.41 \AA$.

Table 3 shows the centralized charges of the oxygen and nitrogen atoms of the amino acid- $\mathrm{Ag}^{+}$systems. As shown in this Table 3, the charge $\mathrm{O}_{1}-\mathrm{GLU}-\mathrm{Ag}^{+}$decreased by $0.45 \%$ compared with the $\mathrm{O}_{1}$-GLU. The values in Table 3 shows that the charge between $\mathrm{O}_{1}$ and the amino acid$\mathrm{Ag}^{+}$was greater than $\mathrm{O}_{1}$ and the free amino acids. In addition, the distance for $\mathrm{O}_{3}-\mathrm{GLU}-\mathrm{Ag}^{+}$and $\mathrm{O}_{4}$-GLU- $\mathrm{Ag}^{+}$

Table 3 Centralized charges of the atoms of the amino acid- $\mathrm{Ag}^{+}$ systems

\begin{tabular}{|c|c|c|c|}
\hline Atom & GLU & $\mathrm{GLU}_{-} \mathrm{Ag}^{+}$ & $\%$ \\
\hline $\mathrm{O}_{1}$ & -0.656 & -0.659 & 0.45 \\
\hline $\mathrm{O}_{2}$ & -0.667 & -0.718 & 7.6 \\
\hline $\mathrm{O}_{3} / \mathrm{N}_{3}$ & -0.625 & -0.805 & 28.8 \\
\hline $\mathrm{O}_{4}$ & -0.628 & -0.794 & 26.4 \\
\hline \multirow[t]{2}{*}{$\mathrm{N}_{5}$} & -1.073 & -0.965 & 10.00 \\
\hline & ILE & ILE-Ag ${ }^{+}$ & \\
\hline $\mathrm{O}_{1}$ & -0.659 & -0.587 & 10.9 \\
\hline $\mathrm{O}_{2}$ & -0.623 & -0.685 & 9.95 \\
\hline \multirow[t]{2}{*}{$\mathrm{O}_{3} / \mathrm{N}_{3}$} & -1.047 & -1.166 & 11.3 \\
\hline & LEU & LEU-Ag ${ }^{+}$ & \\
\hline $\mathrm{O}_{1}$ & -0.651 & -0.586 & 9.98 \\
\hline $\mathrm{O}_{2}$ & -0.625 & -0.686 & 9.76 \\
\hline \multirow[t]{2}{*}{$\mathrm{N}_{3}$} & -1.032 & -1.156 & 12.00 \\
\hline & THR & THR-Ag ${ }^{+}$ & \\
\hline $\mathrm{O}_{1}$ & -0.760 & -0.739 & 2.76 \\
\hline $\mathrm{O}_{2}$ & -0.653 & -0.578 & 11.48 \\
\hline $\mathrm{O}_{3} / \mathrm{N}_{3}$ & -0.626 & -0.691 & 10.38 \\
\hline \multirow[t]{2}{*}{$\mathrm{N}_{4}$} & -1.048 & -1.151 & 9.83 \\
\hline & LYS & LYS-Ag ${ }^{+}$ & \\
\hline $\mathrm{O}_{1}$ & -0.658 & -0.585 & 11.09 \\
\hline $\mathrm{O}_{2}$ & -0.626 & -0.686 & 9.58 \\
\hline $\mathrm{O}_{3} / \mathrm{N}_{3}$ & -1.045 & -1.164 & 11.39 \\
\hline $\mathrm{N}_{4}$ & -1.037 & -1.039 & 0.19 \\
\hline
\end{tabular}


become $28.8 \%$ and $26.4 \%$ smaller than $\mathrm{O}_{3}$-GLU and $\mathrm{O}_{4}$ GLU respectively. On the other hand, the distance for $\mathrm{N}_{5}-\mathrm{GLU}-\mathrm{Ag}^{+}$become $10 \%$ larger than $\mathrm{N}_{5}$-GLU.

As shown in Table 3, the charge for $\mathrm{O}_{2}$-ILE- $\mathrm{Ag}^{+}$ and $\mathrm{N}_{3}$-ILE- $\mathrm{Ag}^{+}$decreased by almost $10 \%$ and $11.3 \%$ compared with $\mathrm{O}_{2}$-ILE and $\mathrm{N}_{3}$-ILE successively. Likewise, the Table 3, the charge for $\mathrm{O}_{2}$-LEU-Ag ${ }^{+}$and $\mathrm{N}_{3}$-LEU$\mathrm{Ag}^{+}$decreased by almost $10 \%$ and $12 \%$ in compared with $\mathrm{O}_{2}$-LEU and $\mathrm{N}_{3}$-LEU respectively. In contrast, the $\mathrm{O}_{1}$ LEU-Ag ${ }^{+}$charge increased by almost $10 \%$ in comparison with $\mathrm{O}_{1}$-LEU.

In Table 3 it can also be seen that both $\mathrm{O}_{1}-\mathrm{THR}-\mathrm{Ag}^{+}$ and $\mathrm{O}_{2}-\mathrm{THR}-\mathrm{Ag}^{+}$charges increased in value, but the $\mathrm{O}_{1}$ THR- $\mathrm{Ag}^{+}$had a value of $2.76 \%$ compared $\mathrm{O}_{1}$-THR and a smaller value compared with the $11.48 \%$ from $\mathrm{O}_{2}$-THR$\mathrm{Ag}^{+}$compared to $\mathrm{O}_{2}$-THR. In addition, the $\mathrm{O}_{3}-\mathrm{THR}-\mathrm{Ag}^{+}$ and $\mathrm{N}_{4}-\mathrm{THR}-\mathrm{Ag}^{+}$charges decreased by almost $11 \%$ in the first case and approximately $10 \%$ in the second compared with the $\mathrm{O}_{3}$-THR and $\mathrm{N}_{4}$, respectively.

Table 3 also shows that charges for $\mathrm{O}_{2}-\mathrm{LYS}_{-} \mathrm{Ag}^{+}, \mathrm{N}_{3}-$ LYS- $\mathrm{Ag}^{+}$, and $\mathrm{N}_{4}-\mathrm{LYS}-\mathrm{Ag}^{+}$became smaller compared to $\mathrm{O}_{2}$-LYS, $\mathrm{N}_{3}$-LYS, and $\mathrm{N}_{4}$-LYS, respectively. The last one decreased by $0.19 \%$ less than the others. The values of the charge distribution on the surfaces of the amino acid molecules before the interactions with $\mathrm{Ag}^{+}$indicate the most polarized points of the structures, see Table 3 .

\section{Conclusions}

We studied five amino acid residues present in the structure of the SARS-CoV-2 spike protein (S), free and interacting spontaneously with silver ions $\mathrm{Ag}^{+}$as protein virucides. We investigated the amino acid- $\mathrm{Ag}^{+}$systems in a gaseous medium and water solvation simulator, obtaining the results of the highest energy occupied orbitals, molecular geometries, electrostatic potentials, and Gibbs free energies, and showed that energy and structural stability were essential.

The maps of electrostatic potential and Mulliken charges showed that the negative charges are centered on the nitrogen atoms of the interaction-free amino acids and the amino acid- $\mathrm{Ag}^{+}$systems.

HOMOs showed that $\mathrm{Ag}^{+}$ions have a greater electronic affinity with the nitrile- $\mathrm{NH}_{2}$ groups than the $\mathrm{C}=\mathrm{O}$ carboxylic group of amino acids.

The calculated Gibbs free energies showed that there is a spontaneous interaction in both systems between the amino acids and $\mathrm{Ag}^{+}$ions, because the entropy increases. Our results indicate that $\mathrm{Ag}^{+}$ions as a chemical agent that inhibits SARS-CoV-2.
However, despite the promising potential of $\mathrm{Ag}^{+}$as a virucide of SARS-CoV-2, impacts on human health need to be investigated.

Funding This article was financed in part by the Federal Institute of Education, Science and Technology of Para - Campus Altamira. Federal University of the South and Southeast of Pará. This investigation was supported by LCC (Laboratório de Computação Científica) of Federal University of the South and Southeast of Pará. Also, this work was computationally supported by the CENAPADSP (Centro Nacional de Processamentode Alto Desempenho) and the LFM (Laboratório de Física Médica) of Federal University of Sergipe.

Author contribution Material preparation, data collection, and analysis were performed by J. Rodrigues, A Novais, A Rodrigues, and G Oliveira. The first draft of the manuscript was written by A Novais, A Rodrigues, G Oliveira, E Novais, and A Rodrigues. All authors commented on previous versions of the manuscript. All authors contributed to the study conception and design and approved the final manuscript.

Availability of data and material The article files will be available upon request.

Code availability The calculations have been carried out using Gaussian09 and Gauss view version provided by Gaussian Inc.

\section{Declarations}

Ethics approval The ethical standards have been met.

Consent to participate Authors consent to participate in the research project, and they assure this research may not bring commercial benefit to us. Our participation is completely voluntary.

Consent for publication The authors declare that they agree with the submission and eventual publication.

Conflict of interest The authors declare that there is nos financial and personal relationships with other people or organizations that could inappropriately influence in this work.

\section{References}

1. Jeremiah SS, Miyakawa K, Morita T, Yamaoka Y, Ryo A (2020) Biochem Biophys Res Commun 533(1):195. https://doi.org/10. 1016/j.bbrc.2020.09.018. https://www.sciencedirect.com/science/ article/pii/S0006291X20317575

2. Hossain S (2021) Int J Nanosci 20(01):2150009. https://doi. org/10.1142/S0219581X21500095

3. Gatadi S, Madhavi Y, Nanduri S (2021) J Molec Struct 1228:129750. https://doi.org/10.1016/j.molstruc.2020.129750. https://www.sciencedirect.com/science/article/pii/S002228602032 0639

4. Galdiero S, Falanga A, Vitiello M, Cantisani M, Marra V, Galdiero M (2011) Molecules 16(10):8894. https://doi.org/10.3390/ molecules16108894. https://www.mdpi.com/1420-3049/16/10/ 8894

5. Nam KH, Kang J, Koh Y (2021) Respir Med Case Rep 33:101399. https://doi.org/10.1016/j.rmcr.2021.101399. https:// www.sciencedirect.com/science/article/pii/S2213007121000617 
6. Pakiari AH, Jamshidi Z (2007) J Phys Chem A 111(20):4391. https://doi.org/10.1021/jp070306t. PMID: 17447742

7. Kulesza A, Mitric R, Bonacic-Koutecky V, Bellina B, Compagnon I, Broyer M, Antoine R, Dugourd P (2011) Angew Chem Int Ed 50(4):878. https://doi.org/10.1002/anie.201005419

8. Sanader Z, Mitric R, Bonacic-Koutecky V, Bellina B, Antoine R, Dugourd P (2014) Phys Chem Chem Phys 16:1257. https://doi.org/10.1039/C3CP52712C

9. Du T, Liang J, Dong N, Lu J, Fu Y, Fang L, Xiao S, Han H (2018) ACS Appl Mater Interf 10(5):4369. https://doi.org/10.1021/acsami.7b13811. PMID: 29337529

10. Medhi R, Srinoi P, Ngo N, Tran HV, Lee TR (2020) ACS Appl Nano Mater 3(9):8557. https://doi.org/10.1021/acsanm.0c01978

11. Sych TS, Buglak AA, Reveguk ZV, Pomogaev VA, Ramazanov RR, Kononov AI (2018) J Phys Chem C 122(45):26275. https://doi.org/10.1021/acs.jpcc.8b08979

12. Shoeib T, Siu KWM, Hopkinson AC (2002) J Phys Chem A 106(25):6121. https://doi.org/10.1021/jp013662z

13. Han J, Chen L, Duan SM, Yang QX, Yang M, Gao C, Zhang BY, He H, Dong XP (2005) Biomed Environ Sci 18(3):176

14. Talebian S, Wallace GG, Schroeder A, Stellacci F, Conde J (2020) Nature Nanotechnology 15:618-624. https://doi.org/10.1038/s41565-020-0751-0

15. Hadrup N, Lam HR (2014) Regulat Toxicol Pharmacol 68(1):1. https://doi.org/10.1016/j.yrtph.2013.11.002. https://www. sciencedirect.com/science/article/pii/S0273230013001864

16. Lyutakov O, Goncharova I, Rimpelova S, Kolarova K, Svanda J, Svorcik V (2015) Mater Sci Eng C 49:534. https://doi.org/10. 1016/j.msec.2015.01.022. https://www.sciencedirect.com/ science/article/pii/S0928493115000326

17. Siegel J, Kolářová K, Vosmanská V, Rimpelová S, Leitner J, Švorčík V (2013) Mater Lett 113:59. https://doi.org/10.1016/j. matlet.2013.09.047. https://www.sciencedirect.com/science/ article/pii/S0167577X13012822

18. Sun Z, Fan C, Tang X, Zhao J, Song Y, Shao Z, Xu L (2016) Appl Surface Sci 387:828. https://doi.org/10.1016/j.apsusc.2016.07. 015. https://www.sciencedirect.com/science/article/pii/S0169433 216314428

19. Sharma VK, Yngard RA, Lin Y (2009) Adv Colloid Interf Sci 145(1):83. https://doi.org/10.1016/j.cis.2008.09.002. https://www. sciencedirect.com/science/article/pii/S0001868608001449

20. Singh M, Singh S, Prasad S, Gambhir IS (2008) Digest Journal of Nanomaterials and Biostructures 3(3):115

21. Morones JR, Elechiguerra JL, Camacho A, Holt K, Kouri JB, Ramírez JT, Yacaman MJ (2005) Nanotechnology 16(10):2346. https://doi.org/10.1088/0957-4484/16/10/059

22. Jung WK, Koo HC, Kim KW, Shin S, Kim SH, Park YH (2008) Amer Soc Microbiol J 74(7):2171. https://doi.org/10.1128/AEM.02001-07

23. Duran N, Marcato P, Conti R, Alves O, Costa F, Brocchi M (2010) Review J Braz Chem Soc 21:949. https://doi.org/10.1590/S0103-50532010000600002

24. Banerjee N, Mukhopadhyay S (2016) VirusDisease 27:1. https://doi.org/10.1007/s13337-015-0293-5

25. Yokoyama K, Ichiki A (2021) Colloid Interf Sci Commun 40:100356. https://doi.org/10.1016/j.colcom.2020.100356. https://www.sciencedirect.com/science/article/pii/ S2215038220301369

26. Babcock GJ, Esshaki DJ, Thomas WD, Ambrosino DM (2004) Amino acids 270 to 510 of the severe acute respiratory syndrome coronavirus spike protein are required for interaction with receptor. J Virol 78(9):4552-4560. https://doi.org/10.1128/JVI.78.9.4552-4560.2004, https:// journals.asm.org/doi/abs/10.1128/JVI.78.9.4552-4560.2004
27. Belouzard S, Millet JK, Licitra BN, Whittaker GR (2012) Viruses 4(6):1011. https://doi.org/10.3390/v4061011. https://www.mdpi. com/1999-4915/4/6/1011

28. Millet JK, Whittaker GR (2018) Virology 517:3. https://doi. org/10.1016/j.virol.2017.12.015. https://www.sciencedirect.com/ science/article/pii/S0042682217304208. Nidovirus Research

29. Frisch MJ, Trucks GW, Schlegel HB, Scuseria GE, Robb MA, Cheeseman JR, Scalmani G, Barone V, Petersson GA, Nakatsuji $\mathrm{H}$, Li X, Caricato M, Marenich A, Bloino J, Janesko BG, Gomperts R, Mennucci B, Hratchian HP, Ort JV, Fox DJ (2009) Gaussian 09

30. Berman HM, Westbrook J, Feng Z, Gilliland G, Bhat TN, Weissig H, Shindyalov IN, Bourne PE (2000) Nucleic Acids Res 28(1):235. https://doi.org/10.1093/nar/28.1.235

31. Yurkovetskiy L, Wang X, Pascal KE, Tomkins-Tinch C, Nyalile TP, Wang Y, Baum A, Diehl WE, Dauphin A, Carbone C et al (2020) Cell 183(3):739. https://doi.org/10.1016/j.cell.2020. 09.032

32. Pettersen EF, Goddard TD, Huang CC, Couch GS, Greenblatt DM, Meng EC, Ferrin TE (2004) J Computat Chem 25(13):1605. https://doi.org/10.1002/jcc.20084

33. Lee C, Yang W, Parr RG (1988) Phys Rev B 37:785. https://doi.org/10.1103/PhysRevB.37.785

34. Becke AD (1993) J Chem Phys 98(7):5648. https://doi.org/10. 1063/1.464913

35. Shannon A, Le NTT, Selisko B, Eydoux C, Alvarez K, Guillemot JC, Decroly E, Peersen O, Ferron F, Canard B (2020) Antiv Res 178:104793. https://doi.org/10.1016/j.antiviral.2020.104793. https://www.sciencedirect.com/science/article/pii/ S0166354220302072

36. Sun Z, Ostrikov KK (2020) Sustain Mater Technol 25:e00203. https://doi.org/10.1016/j.susmat.2020.e00203. https://www. sciencedirect.com/science/article/pii/S2214993720305443

37. Machado MR, Pantano S (2020) J Chem Theor Comput 16(3):1367. https://doi.org/10.1021/acs.jctc.9b00953. PMID: 31999456

38. Case DA, Darden T, Cheatham TE III, Simmerling C, Wang J, Duke RE, Luo R, Merz KM, Pearlman DA, Crowley $M$ et al (2006) University of california, San Francisco 45

39. Amin NAS, Yaw TC (2007) Int J Hydro Energ 32(12):1789. https://doi.org/10.1016/j.ijhydene.2006.12.004. https://www. sciencedirect.com/science/article/pii/S0360319906006124

40. Peng XL, Jiang R, Jia CS, Zhang LH, Zhao YL (2018) Chem Eng Sci 190:122. https://doi.org/10.1016/j.ces.2018.06.027. https:// www.sciencedirect.com/science/article/pii/S0009250918303956

41. Peng XL, Jiang R, Jia CS, Zhang LH, Zhao YL (2018) Chem Eng Sci 190:122. https://doi.org/10.1016/j.ces.2018.06.027. https:// www.sciencedirect.com/science/article/pii/S0009250918303956

42. Jia CS, Zhang LH, Peng XL, Luo JX, Zhao YL, Liu JY, Guo JJ, Tang LD (2019) Chem Eng Sci 202:70. https://doi.org/10.1016/j.ces.2019.03.033. https://www. sciencedirect.com/science/article/pii/S0009250919302489

43. Popovic M, Minceva M (2020) Heliyon 6(9):e04943. https://doi.org/10.1016/j.heliyon.2020.e04943. https://www. sciencedirect.com/science/article/pii/S2405844020317862

44. Buglak AA, Ramazanov RR, Kononov AI (2019) Amino Acids 51(5):855. https://doi.org/10.1007/s00726-019-02728-z

45. Rad AS, Ardjmand M, Esfahani MR, Khodashenas B (2021) Spectrochim Acta Part A Molecul Biomolecul Spectroscop 247:119082. https://doi.org/10.1016/j.saa.2020.119082. https:// www.sciencedirect.com/science/article/pii/S1386142520310611

46. Reed AE, Weinhold F (1985) J Chem Phys 83(4):1736. https://doi.org/10.1063/1.449360 
47. Gökce1 H, Bahçeli S, Akyildirim O, Yüksek H, Kol OG (2013) Lett Org Chem 10(6):395. https://doi.org/10.2174/ 15701786113109990001

48. Noureddine O, Issaoui N, Al-Dossary O (2021) J King Saud Univ Sci 33(1):101248. https://doi.org/10.1016/j.jksus.2020.101248. https://www.sciencedirect.com/science/article/pii/ S1018364720303621

49. Gokce H, Bahceli S, Akyildirim O, Yuksek H, Kol OG (2013) Lett Org Chem 10(6):395. https://doi.org/10.2174/ 15701786113109990001
50. Mulliken RS (1955) J Chem Phys 23(10):1833

51. Rostamoghli R, Vakili M, Banaei A, Pourbashir E, Jalalierad K (2018) Chem Rev Lett 1(1):31

52. dos Santos Pereira AK, Nakahata DH, Manzano CM, de Alencar Simoni D, Pereira DH, Lustri WR, Formiga ALB, Corbi PP (2019) Polyhedron 114116:173

Publisher's note Springer Nature remains neutral with regard to jurisdictional claims in published maps and institutional affiliations. 